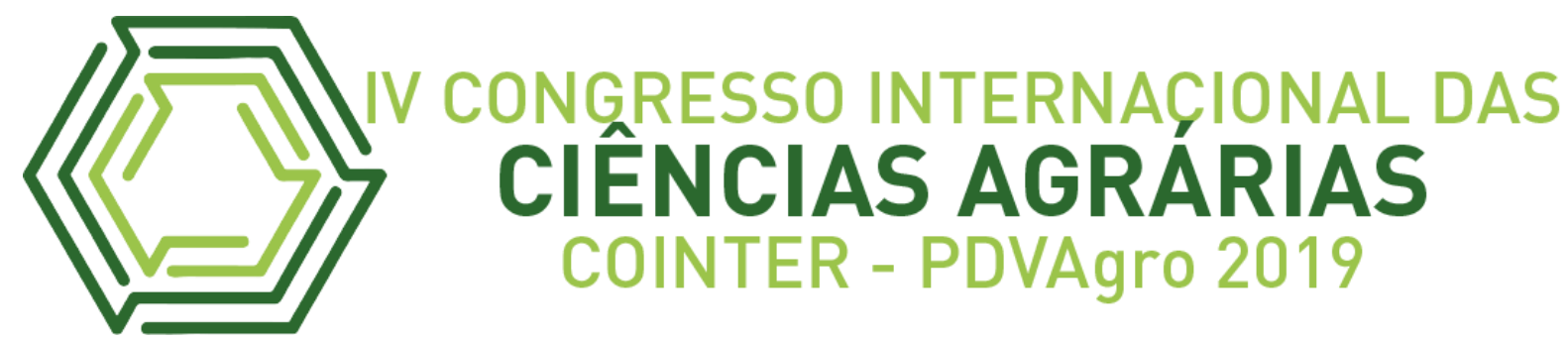

\title{
ANÁLISE DE MÉTODOS DE TRANSFORMAÇÃO DO CAFÉ E SUA POSSÍVEL EFICÁCIA NO RAMO AGRÍCOLA
}

\section{ANÁLISIS DE LOS MÉTODOS DE TRANSFORMACIÓN DEL CAFÉ Y SU POSIBLE EFICIENCIA AGRÍCOLA}

\section{ANALYSIS OF COFFEE TRANSFORMATION METHODS AND THEIR POSSIBLE AGRICULTURAL EFFICIENCY}

\author{
Apresentação: Comunicação Oral
}

Jair Soares da Silva Filho ${ }^{1}$, Dayane Nunes Barros ${ }^{2}$; Suzana Pedroza da Silva ${ }^{3}$

DOI: $\underline{\text { https://doi.org/10.31692/2526-7701.IVCOINTERPDVAgro.2019.0081 }}$

\begin{abstract}
Resumo
A biotecnologia estuda a manipulação de material genético com o objetivo de atingir as características procuradas para determinado organismo. A modificação em alimentos busca potencializar a qualidade e resistência mantendo características sensoriais importantes daquele produto a fim de agregar valor comercial. Nas culturas de café, o isolamento de genes procura aumentar a produtividade e qualidade das espécies. Atualmente no Brasil, as espécies mais cultivadas são Coffea arabica (Arábica) e Coffea canephora (Robusta e Conilon), com características de baixa variabilidade genética e com grande extensibilidade geográfica, respectivamente. $\mathrm{O}$ objetivo do seguinte estudo foi, através de revisões bibliográficas, das atuais manipulações genéticas aplicadas aos cultivares de café das espécies $C$ canephora e $C$. arabica, como também estudar as consequências destas modificações nas safras. Para realização deste trabalho foram utilizados artigos científicos e patentes encontradas nas seguintes plataformas de dados: Web of Science Scielo, Researchgate, Springer e Agritop; a cronologia determinada foi de 2015 a 2019, totalizando 10 artigos e uma patente. Os resultados mostraram que os métodos de transformação mais utilizados foram através da mediação por Agrobacterium, bombardeamento de partículas e propagação de plantas in vitro, cujo direcionamento propõe o desenvolvimento das espécies a fim de impulsionar a economia e propagar as espécies de café com menor tempo de plantio. Conclui-se que o método mais empregado se dá através da mediação por Agrobacterium, com ênfase na espécie $A$. tumefaciens. Contudo, existem novos métodos em estudo cujo potencial é de provocar maior aceitabilidade e praticidade por parte da produção de safras de café.
\end{abstract}

Palavras-Chave: Biotecnologia, Café, Manipulações genéticas.

\footnotetext{
${ }^{1}$ Graduando em Engenharia de Alimentos, UFRPE, Garanhuns, jair-soares1@hotmail.com

${ }^{2}$ Graduanda em Engenharia de Alimentos, UFRPE, Garanhuns, dayanenunes1811@outlook.com

${ }^{3}$ Doutora em Engenharia Química, UFRPE, Garanhuns, suzpedroza@gmail.com
} 


\title{
Resumen
}

La biotecnología estudia la manipulación de material genético para lograr las características buscadas para un organismo en particular. La modificación en los alimentos busca mejorar la calidad y la resistencia al tiempo que mantiene importantes características sensoriales de ese producto para agregar valor comercial. En los cultivos de café, el aislamiento de genes busca aumentar la productividad y la calidad de las especies. Actualmente en Brasil, las especies más cultivadas son Coffea arabica (Arábica) y Coffea canephora (Robusta y Conilon), con características de baja variabilidad genética y gran extensibilidad geográfica, respectivamente. El objetivo del siguiente estudio fue, a través de revisiones bibliográficas, las manipulaciones genéticas actuales aplicadas a los cultivares de café de las especies $C$. canephora y $C$. arabica, así como estudiar las consecuencias de tales modificaciones en los cultivos. Para este trabajo utilizamos artículos científicos y patentes que se encuentran en las siguientes plataformas de datos: Web of Science Scielo, Researchgate, Springer y Agritop; la cronología determinada fue de 2015 a 2019, totalizando 10 artículos y una patente. Los resultados mostraron que los métodos de transformación más utilizados fueron a través de la mediación de Agrobacterium, el bombardeo de partículas y la propagación de plantas in vitro, cuya dirección propone el desarrollo de especies para impulsar la economía y propagar especies de café con un tiempo de siembra más corto. Se concluye que el método más utilizado es a través de la mediación de Agrobacterium, con énfasis en las especies de A. tumefaciens. Sin embargo, hay nuevos métodos en estudio cuyo potencial es aumentar la aceptabilidad y practicidad de la producción de café.

Palabras Clave: Biotecnología, Café, Manipulaciones genéticas.

\begin{abstract}
Biotechnology studies the manipulation of genetic material in order to achieve the characteristics sought for a particular organism. Modification in food seeks to enhance quality and strength while maintaining important sensory characteristics of that product in order to add commercial value. In coffee crops, gene isolation seeks to increase species productivity and quality. Currently in Brazil, the most cultivated species are $C$. arabica and $C$. canephora, with characteristics of low genetic variability and great geographic extensibility, respectively. The objective of the following study was, through bibliographic reviews, the current genetic manipulations applied to coffee cultivars of Coffea canephora (Robusta and Conilon) and Coffea arabica (Arábica) species, as well as to study the consequences of such modifications in the crops. For this work we used scientific articles and patents found on the following data platforms: Web of Science Scielo, Researchgate, Springer and Agritop; the determined chronology was from 2015 to 2019, totaling 10 articles and one patent. The results showed that the most used transformation methods were through Agrobacterium mediation, particle bombardment and propagation of plants in vitro, whose direction proposes the development of species in order to boost the economy and propagate coffee species with shorter planting time. . It is concluded that the most used method is through Agrobacterium mediation, with emphasis on A. tumefaciens species. However, there are new methods under study whose potential is to increase the acceptability and practicality of coffee crop production.
\end{abstract}

Keywords: Biotechnology, Coffee, Genetic Manipulations. 


\section{Introdução}

A modificação genética é a área da biotecnologia que se ocupa com a manipulação do material genético em organismos vivos, permitindo-lhes realizar funções específicas (RAMAN, 2017). Quanto aos alimentos, busca-se promover métodos capazes de potencializar as qualidades e resistência de determinado produto, com a finalidade de agregar valor comercial ao mesmo.

No caso das culturas de café, através de pesquisas em biotecnologia, foi dada importância a análises em isolamento de genes para melhorar a produção e qualidade do cafeeiro, como também sua adaptabilidade ao ambiente. Comercialmente apenas duas espécies de café são cultivadas extensivamente: Coffea arabica (Arábica) e Coffea canephora (Robusta e Conilon) (KUMAR, 2006). Ainda segundo Kumar (2006), a espécie C. canephora apresenta distribuição geográfica bastante ampla, além de se desenvolver a baixas altitudes, representando $80 \%$ da produção de café africano, porém também cultivada em países americanos e asiáticos. De acordo com Almeida et al. (2008), a transgenia aplicada a espécie C. arabica demonstra ser uma boa maneira de obter plantas mais adequadas a diferentes propósitos, uma vez que sua variedade é a mais importante, é perene, tetraplóide e tem baixa variabilidade genética.

Portanto, esse trabalho possui como objetivos analisar as diversas formas de manipulações genéticas aplicadas aos cultivares de café, mais especificamente aos cultivares de $C$. canephora e $C$. arabica assim como estudar as consequências de tais safras geneticamente modificadas na agricultura moderna.

\section{Fundamentação Teórica}

Acredita-se que o café já era consumido antes de Cristo, contudo sua origem teria sido na Etiópia, sendo chamado de kahwa, foi levado para Arábia que se tornou o primeiro polo agrícola e comercial cafeeiro (REGO \& PAULA, 2012). O café chegou ao Brasil por volta de 1727, através de Francisco Mello Palheta, as mudas trazidas foram plantadas em Belém (Pará) e no Maranhão, chegando ao Rio de Janeiro no ano de 1760, a economia cafeeira se estabilizou no ano 1860, onde o porto comercial de maior interesse econômico era o do Rio de Janeiro com o porto de Santos sendo o maior exportador. A partir da proclamação da república foi dada a era do café, sendo o país detentor de $45 \%$ da produção mundial; no século 19 o café 
era o maior artigo de exportação com os Estados Unidos comprando $50 \%$ da produção (BNDES, 1999).

Foi criado em 1952 o Instituto Brasileiro do Café (IBC) o setor tinha o intuito de controlar e coordenar a produção e comercialização interna e externa, dando assistência também para as indústrias para aperfeiçoamento das técnicas de beneficiamento (BNDES, 1999).

O café atualmente é amplamente consumido através de infusão dos grãos, principalmente blends de Coffea canephora (robusta e conilon) e Coffea arábica, sendo conhecida como uma bebida de propriedades estimulantes, adquirida pela presença de cafeína e ácidos clorogênicos, que possuem capacidade antioxidante (DURÁN et al., 2017).

Atualmente o Brasil é o maior produtor de café, possuindo cerca de 2,2 milhões de hectares, que compreendem 15 estados, dentre eles: Bahia, Acre, Mato Grosso do Sul, São Paulo, Rondônia, Pernambuco, Paraná e Pará, os maiores produtores são: Minas Gerais e Espírito Santo, sendo as espécies mais cultivadas arábica e conilon. No ano de 2015 74\% da produção nacional correspondeu ao café arábica e $26 \%$ ao café conilon (DURÁN et al., 2017). O café possui um valor de mercado volátil, devido a diversos fatores não relacionados diretamente ao mercado, tais como o clima, o qual é considerado um fator não sistêmico que impacta diretamente na produtividade e no preço (REGO \& PAULA, 2012).

O café conilon é uma espécie amplamente cultivada no Espírito Santo, em 2011 a produção estadual atingiu 8,5 milhões de sacas, representando $20 \%$ da produção nacional e $76 \%$ da produção de café conilon no Brasil (INCAPER, 2012). A qualidade do produto está diretamente relacionada a características de pré e pós colheita, assegurando características de sabor e aroma, a operação de secagem é a que mais tem influência no produto final (THOMAZINI et al., 2011).

O café arábica é uma espécie comercializada mundialmente, representando $70 \%$ do mercado mundial, é caracterizada como uma bebida de alta qualidade, com essência marcante e sabor adocicado, sendo consumida pura ou em blends com outras espécies (EMBRAPA, 2004).

Quanto ao campo da engenharia genética, genes de determinado organismo podem ser isolados e depois transferidos para outro organismo proveniente de uma espécie distinta, acrescentando-lhe novas características genéticas (AZEVEDO \& FUNGARO, 2000). Com o acréscimo da biotecnologia aplicada ao café, por meio de técnicas de cultura de tecidos 
vegetais, marcadores moleculares e transformação genética, é possível afirmar que tais fatores constituem ferramentas importantes para a manutenção e conservação do germoplasma, cuja utilidade é direcionada a criação de novas cultivares, assim como na obtenção de novos materiais genéticos em tempo reduzido, além da identificação, avaliação e multiplicação de novos genótipos (MORAIS \& MELO, 2011).

Os primeiros métodos de transformação de café, realizados via eletroporação, constituíam-se na integração de DNA proveniente de outras espécies em protoplastos (BARTON et al., 1991). Contudo, tal método mostrou-se pouco eficiente, levando às tentativas de transformação utilizando Agrobacterium como vetor (SPIRAL et al., 1993).

Pode-se também citar outra forma de manipulação genética aplicada ao café, cuja metodologia se dá através da modificação e biossíntese de etileno e de cafeína, além do protocolo de transformação em café via biobalística ou bombardeamento de células vegetais, método de alta eficiência de transformação cuja presença do gás hélio comprimido possibilita a introdução de genes de interesse como também genes marcadores em células vegetais (MORAIS \& MELO, 2011).

Graças às técnicas de transformação genética, o avanço por parte do melhoramento genético do cafeeiro pode se desenvolver com maior rapidez possibilitando a geração de novas cultivares ou genótipos direcionados a programas de melhoramento genético convencional (MORAIS \& MELO, 2011). Quanto à agricultura, deverão ser aceitas plantas geneticamente modificadas desde que haja benefícios aos produtores, consumidores como também as empresas, sem danos ao meio ambiente. (AZEVEDO \& FUNGARO, 2000).

\section{Metodologia}

Para realização desse trabalho, buscaram-se artigos científicos e patentes em relevantes bases de dados (Web of Science, Scielo, Researchgate, Springer e Agritop) que relatassem pesquisas relacionadas ao plantio, produção e uso de café transgênico. As palavras-chave utilizadas, em diferentes combinações durante a pesquisa, foram: café, eletroporação, transgênico, transgenic, coffee. A cronologia realizada durante a pesquisa foi delimitada entre os anos de 2005 a 2019. Depois, filtraram-se os resultados considerando apenas os trabalhos acadêmicos e patentes durante o período de 2015 a 2019, totalizando 10 artigos e uma patente sobre o tema. 


\section{Resultados e Discussão}

Quanto à produção dos trabalhos, dois são originários apenas de instituições nacionais (1), quatro são originários de pesquisas conjuntas entre instituições nacionais e internacionais (2) e cinco são originários apenas de instituições internacionais (3), conforme mostra a Figura 1 abaixo.

Figura 1. Quantitativo de trabalhos utilizados para a revisão bibliográfica do presente estudo.

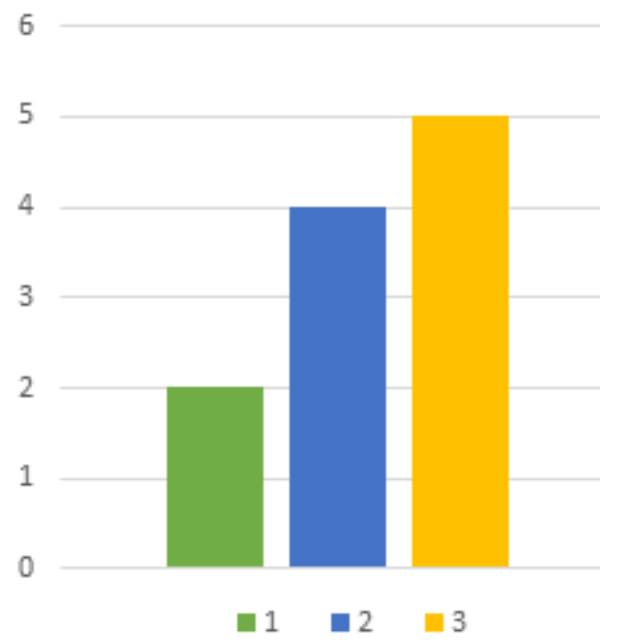

Fonte: Própria (2019).

No trabalho produzido por Ribas et al. (2006), foi feita uma revisão com o intuito de fornecer atualizações relacionadas à transgenia aplicada ao café, além de discutir sobre a utilidade desta tecnologia, apresentando estratégias de transformação via bombardeamento de partículas como também o uso de Agrobacterium tumefaciens. Segundo os autores, parâmetros como protocolos de cultura de tecidos eficientes, sistemas seletivos confiáveis e o próprio método de transformação são essenciais quanto ao processo de transformação do café. No entanto, embora seja complexo atingir estes parâmetros direcionados à transformação, os autores destacam os diferentes grupos de pesquisa cujos trabalhos focaram na transformação das espécies Coffea usando Agrobacterium e métodos via biobalística ou eletroporação. As variedades $C$. arábica e $C$. canephora, ainda segundo os pesquisadores, atingiram a fase adulta apenas através dos dois primeiros métodos. Logo, entende-se que as condições necessárias para o processo de transformação do café precisam apresentar eficiência e devem estar interligadas entre si, devido a importância de cada uma, no que se refere a transformação do café. Além disso, é preciso ater-se aos métodos cujos resultados sejam também eficientes, 
como no caso do desenvolvimento das espécies C. canéfora e C. arábica, cuja fase adulta foi apenas atingida através das transformações via Agrobacterium e biobalística.

Entretanto no trabalho realizado por Alpizar et al. (2006) sobre a produção de raízes transformadas de duas variedades das espécies $C$. arabica, Caturra e IAPAR-59 após infecção causada pelo Agrobacterium rhizogenes. Esse estudo pôde comprovar que tais raízes retêm o fenótipo de resistência/sensibilidade das variedades das quais são derivadas, como também sugerem, através dos resultados, que plantas compostas podem ser utilizadas em estudos referentes às análises de genes de resistência a nematóides. Através da análise dos dois estudos, entende-se que processo de infecção de hipocótilos de embrião germinados com A. rhizogenes demonstrou ser mais útil se comparado com o processo relatado pelo trabalho de Ribas et al. (2006), no que se refere a transformação mediada por A. tumefaciens.

$\mathrm{O}$ resultado final apresentado pelo A. rhizogenes levou cinco meses para produzir plantas compostas de aclimatação. A validação eficiente e o estudo funcional de genes de resistência a nematóides tornou-se possível graças ao desenvolvimento considerável dos porta-enxertos apresentados por tais plantas. Porém, geralmente são necessários catorze meses para produzir plântulas similares transformadas e bem desenvolvidas, através da transformação mediada por A. tumefaciens com pressão seletiva, começando a partir de explantes primários (Hatanaka et al. 1999; Leroy et al. 2000). Logo, através das análises feitas por Alpizar et al. (2006), pode-se perceber que protocolos de transformação utilizando o A. tumefaciens não são eficientes quanto ao estudo de genes de resistência a nematóides em outras espécies de plantas, particularmente em plantas lenhosas, que é o caso do café.

Como adendo, no trabalho realizado por Mishra et al. (2010), é possível ver, graças a uma proteína fluorescente verde, também nomeada por Green Fluorescent Protein (GFP), células transformadas provenientes de um processo de transformação mediado por Agrobacterium. Esta proteína é utilizada como um marcador de seleção visual para a produção de café transgênico. Os autores utilizaram calos embriogênicos somáticos derivados de hipocótilos e folhas cotiledonares de plântulas cultivadas in vitro para a transformação mediada por Agrobacterium. As pesquisas indicaram que uma combinação de seleção visual baseada em fluorescência GFP e baixo nível de antibióticos (higromicina B $10 \mathrm{mg} / \mathrm{L}$ ) foi mais efetiva do que a análise isolada de cada aspecto. Tal conclusão é tomada observando a proliferação de células não transformadas, cujo aumento não foi eficiente, mesmo em baixa concentração de antibióticos, o que facilitou a separação das células fluorescentes. 
Analisando o trabalho feito por Albuquerque et al. (2009), foi utilizado o método de bombardeamento em calos embriogênicos para a modificação genética de $C$. arabica. Os pesquisadores chegaram à conclusão de que tal método pode ser efetivamente usado para introduzir genes nas espécies de C. arabica. Os resultados apresentaram desenvolvimento normal das plantas, enquanto as sementes geneticamente modificadas apresentaram um padrão de segregação mendeliana da expressão do gene uidA em seus embriões zigóticos. Assim como no trabalho apresentado por Mishra et al. (2010), cujo sistema de marcadores utilizados foram de seleção visual, Albuquerque et al. (2009) também utilizou um sistema de marcadores, realizado através do promotor dCaMV35s, que levou a expressão do gene uidA em grãos de café. O gene uidA foi detectado nas espécies transformantes de C. arábica através da reação em cadeia da polimerase (abreviatura em inglês PCR).

Entretanto para o artigo produzido por Kumar et al. (2006) que analisa a propagação de plantas in vitro e a melhoria de culturas do café, através de aspectos básicos e aplicados na área da biotecnologia. Os autores sugerem que culturas de tecido podem ser utilizadas em métodos de multiplicação, sendo uma alternativa viável para a propagação do café, além de permitir a produção de plantas com características moderadamente uniformes e em escala maciça durante curto espaço de tempo. De acordo com os pesquisadores, os atuais métodos de transformação genética, como a absorção direta de DNA, bombardeamento de genes, mediação por Agrobacterium e infiltração a vácuo podem permitir que o cultivo de café avançe com trabalhos destinados a desenvolver plantas resistentes a pragas, doenças do café e herbicidas, além de outras características específicas.

Porém, segundo Almeida et al. (2008), promotores constitutivos têm sido destinados à produção de organismos geneticamente modificados. Todavia, a expressão indiscriminada de genes heterólogos é restrita devido a implicações ambientais, econômicas e de biossegurança. Logo, os autores abordaram o uso de promotores capazes de resolver esses problemas através da limitação de expressão de um transgene aos tecidos e condições necessários. Uma vez validados, tais promotores são importantes para a obtenção de organismos geneticamente modificados destinados a diversas situações, como seca e resistência a patógenos. Os autores concluem que culturas podem se desenvolver futuramente através do desenvolvimento de novos promotores com padrões de expressão específicos para tecidos.

Quanto a pesquisa feita por Albuquerque et al. (2015), os pesquisadores concluíram que o promotor PHA-L pode ser utilizado em grãos de café com a função de guiar a expressão 
de transgene específica de sementes, tornando-se assim um recurso valioso para o controle de transgenes em análises direcionadas ao melhoramento de plantas.

Quanto ao estudo realizado por Aquino et al. (2018), foram feitas análises com a espécie $C$. canephora, no que se refere a haplótipos promotores pertencentes ao gene CcDREB1D, com o intuito de aplicá-los na espécie Nicotina tabacum (tabaco). Como resultado, o sistema transcricional do tabaco reconheceu os haplótipos promotores do café e sua regulação foi dada por diversas maneiras devido ao estresse abiótico.

Analisando o trabalho patenteado por Ferreira et al. (2013), pesquisadores conseguiram aprimorar, através da biotecnologia, espécies vegetais de cunho comercial. O estudo de modificação genética conseguiu produzir plantas com maior tolerância para com déficit hídrico e estresse salino, graças à expressão do gene CAHB12 presente na espécie $C$. arabica. É importante também citar o estudo realizado por Ashihara et al. (2006) que teve como tema a "biossíntese de cafeína e metabolismo de adenina na espécie $C$. canephora com expressão reduzida dos genes N-metiltransferase".

Quanto ao número de pesquisas realizadas com A. tumefaciens e A. rhizogenes na presença de dois explantes, sendo eles embriões somáticos e tecidos embriogênicos, pertencentes às espécies $C$. arábica e $C$. canephora, foram utilizados dados do trabalho de Ribas et al. (2006), onde o autor os complementou a partir do trabalho realizado por Spiral et al. (1999) com pesquisas realizadas entre os anos de 1991 à 2006, conforme mostram os gráficos das Figuras 2, 3, 4 e 5. De acordo com os dados presentes nos gráficos, pode-se perceber que, durante o período de 1991 a 1997, foram realizadas 7 pesquisas utilizando métodos de transformação via Agrobacterium aplicados em embriões somáticos. Porém, não houve pesquisas com os mesmos métodos de transformação aplicados em tecidos embriogênicos durante o mesmo período. Todavia, dos anos 1999 a 2006, há a ocorrência de estudos com o intuito de aplicar tais métodos de transformação em tecidos embriogênicos, totalizando 2 pesquisas direcionadas a espécie C. arabica e 5 pesquisas direcionadas a espécie C. canephora com utilização de tal explante. Nesse mesmo período, foram realizadas 2 pesquisas na espécie $\mathrm{C}$. arabica quanto a aplicação dos mesmos métodos de transformação em embriões somáticos, enquanto a espécie C. canephora foi utilizada em 5 pesquisas com o mesmo objetivo.

Figuras 2 e 3. Quantidade de pesquisas realizadas com A. tumefaciens e A. rhizogenes como métodos de transformação em embriões somáticos e tecidos embriogênicos. 


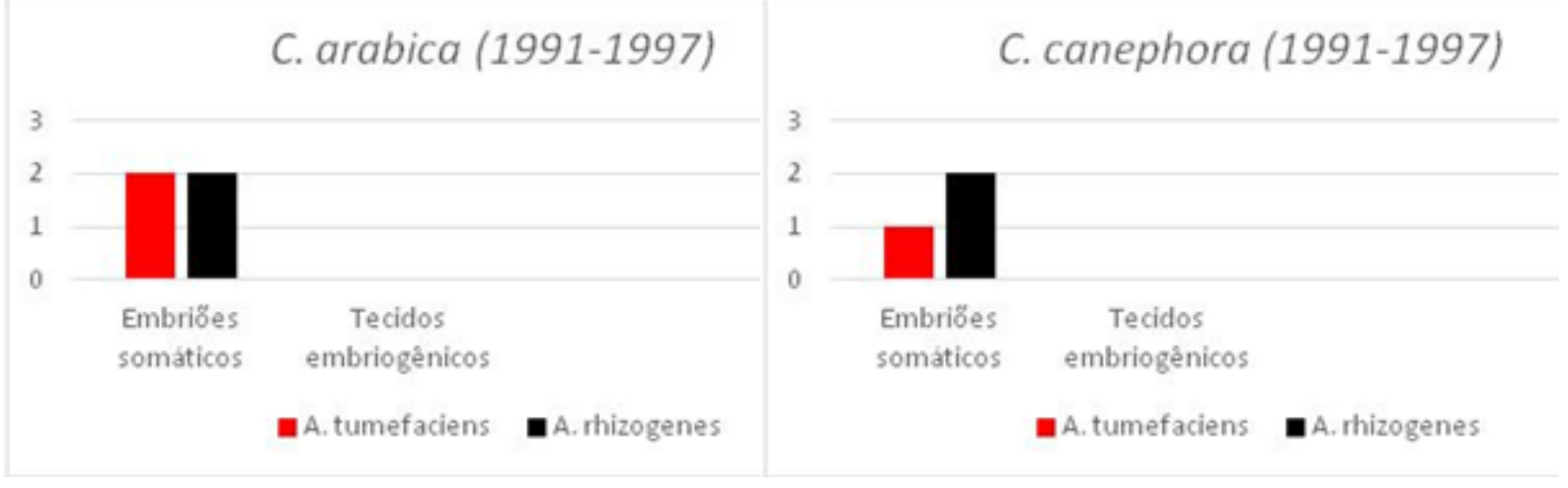

Fonte: Spiral et al. (1999).

Figuras 4 e 5. Quantidade de pesquisas realizadas com A. tumefaciens e A. rhizogenes como métodos de transformação em embriões somáticos e tecidos embriogênicos.

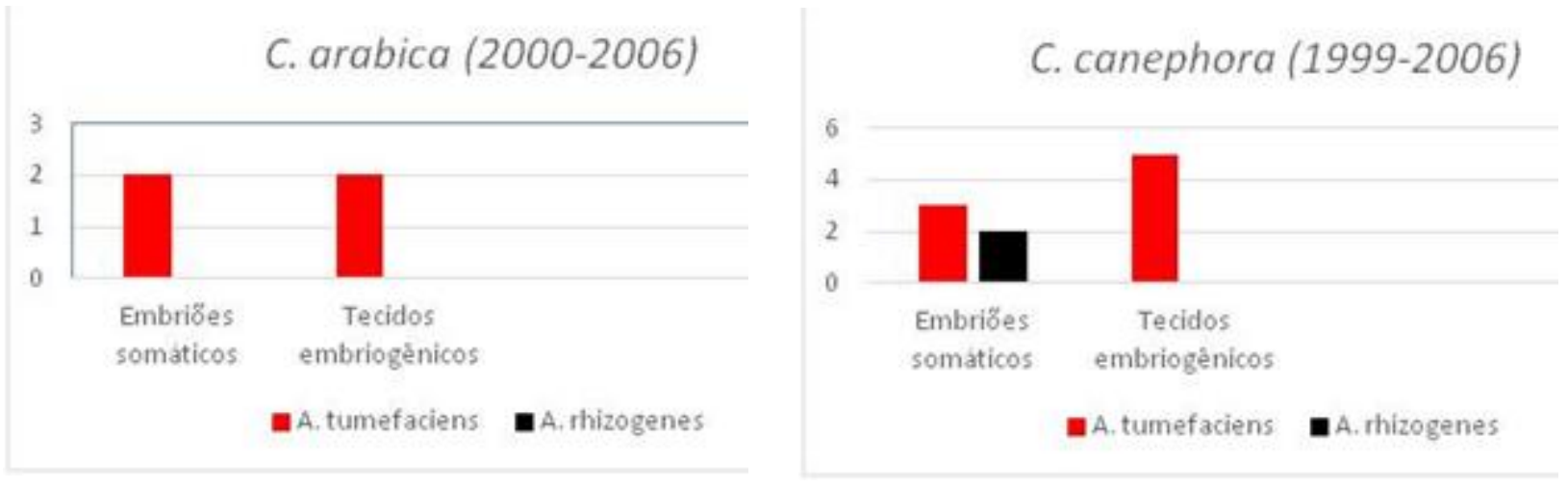

Fonte: Ribas et al. (2006)

A partir de todos os dados obtidos na revisão feita para o presente trabalho e analisando a conclusão de Raman (2017), entende-se que a tecnologia direcionada à agricultura deve apresentar avanços significativos caso a transgenia seja aplicada nas culturas de cunho comercial. Organismos geneticamente modificados são uma forma rápida e inovadora para atender às demandas da população mundial. Contudo, ainda segundo Raman (2017), é necessário que haja uma comunicação científica mais aberta entre o ramo agrícola e órgãos responsáveis por estudos relacionados a transgênicos, com o intuito de evitar problemas posteriores envolvendo pesquisas antiéticas e desinformação por parte do público em geral. Segundo Raman (2017), transgênicos podem adquirir maior aceitabilidade através da aplicação estrita de regulamentos monitorados e implementados por órgãos agrícolas dos governos, como a lei 11.105 de 2005, cuja aplicação se refere ao uso de OGMs (organismos geneticamente modificados) através de normas de segurança e mecanismos de fiscalização 
estabelecidos (Abreu, 2009), assim como o diálogo entre produtores e consumidores, além de estratégias globais de atenuação de riscos, assegurando assim a prevenção de eventuais problemas relacionados à transgenia.

\section{Conclusões}

Constata-se, portanto, que há diversas formas de manipulação genética relacionados a transformação de espécies do café, mais especificamente nas espécies C. canephora e C. arabica. Os pesquisadores devem utilizar os métodos cuja aplicabilidade seja eficiente quanto ao objetivo a que se propõem, sejam eles relacionados a melhorias tais como o aumento da produção de grãos, desenvolvimento mais rápido da planta, ou resistência a pragas e ambientes com estresse abiótico. Apesar do método de transformação via Agrobacterium tumefaciens ter sido utilizado diversas vezes em estudos relacionados à transformação das espécies C. canephora e C. arabica, pode-se perceber que novas pesquisas vêm apresentando métodos mais eficientes para a modificação genética do café. Além de tal método, devem ser observados os outros processos de transformação, tais como a modificação genética via biobalística e bombardeamento de partículas como também a propagação das espécies in vitro, visando os melhores resultados, ao mesmo tempo em que são utilizados explantes convenientes ao objetivo proposto. A utilização de marcadores durante o processo de transformação também mostra-se importante para a identificação posterior dos genes introduzidos nas espécies de café.

Alterações no DNA do café prometem alavancar a indústria agrícola, e consequentemente, a economia de seu respectivo país. A transgenia pode representar avanços tecnológicos nas safras de C. canephora e C. arábica, já que as respectivas plantas podem ser submetidas a uma gama de melhorias cujos fatores podem beneficiar tanto o nível de produção dos cafeeiros, como também sua capacidade de resistir a diversas a condições adversas que venham a ser prejudiciais aos produtores. No entanto, é essencial que haja diálogo entre população, pesquisadores e produtores, para a aplicação, produção e posterior venda de grãos modificados do café, com métodos que não prejudiquem o meio ambiente e a saúde dos consumidores.

\section{Referências}

ABREU. A.; ROSSINHOLI. M.; CARRERO, C. C.; ANDRADE. L. M.; SANTOS. T. Z. 
Transgênicos e as Empresas: discussões atuais. UNIVEM. Marília. SP. 2009. Disponível em: <sober.org.br/palestra/13/850.pdf> Acesso em: 29 ago 2019;

ALBUQUERQUE, É.V.S., BEZERRA, C. A., ROMERO, J. V., VALENCIA, J. W. A., VALENCIA-JIMÉNEZ, A., PIMENTA, L. M., BARBOSA, A. E. A. D., SILVA, M. C. M., MENEGUIM, A. M., SÁ, M. E. L., ENGLER, G., DE ALMEIDA-EGLER, J., FERNANDEZ, D., GROSSI-DE-SÁ, M.F. Seed-Specific Stable Expression of the $\alpha$-AI1 Inhibitor in Coffee Grains and the In Vivo Implications for the Development of the Coffee Berry Borer. Tropical Plant Biol. v.8, n.3-4, p. 98-107, dez. 2015.

ALBUQUERQUE, E.V.S., CUNHA, W.G., BARBOSA, A.E.A.D. COSTA, P.M., TEIXEIRA, J.B., VIANNA, G.R., CABRAL, G.B., FERNANDEZ, D., GROSSI-DE-SA, M.F. Transgenic coffee fruits from Coffea arabica genetically modified by bombardment. In Vitro Cell.Dev.Biol.-Plant. v. 45, n 5, p. 532-539, out. 2009.

ALMEIDA, J. D. de; BARROS, L.M.G.; SANTOS, D.B.M.; COTTA, M.G.; BARBOSA, E.A.; CAÇÃO S.B.; EIRA, M.T.S.; ALVES, G.S.C., VINECKY, F., PERREIRA, L.F.P., SILVA, F., ANDRADE da, A.C., MARRACCINI, P., CARNEIRO, M.. Prospection of tissue specific promoters in coffee. In : 22nd International Conference on Coffee Science. 2008 Disponível em: <https://www.cabdirect.org/cabdirect/abstract/20093174725> Acesso em: 29 ago 2019.

ALPIZAR, E., DECHAMP, E., ESPEOUT, S., ROYER, M., LECOULS, A.C., NICOLE, M., BERTRAND, B., LASHERMES, P., ETIENNE, H. Efficient production of Agrobacterium rhizogenes-transformed roots and composite plants for studying gene expression in coffee roots. Plant Cell Rep. v. 25, n 9, p. 959-967, set. 2006.

AQUINO, S.O., ARAÚJO C., F., RÊGO, E.C.S., ALVES, G.S.C., ANDRADE, A.C., MARRACCINI, P. Functional analysis of different promoter haplotypes of the coffee (Coffea canephora) CcDREB1D gene through genetic transformation of Nicotiana tabacum. Plant Cell Tiss Organ Cult v.132, n.2, p. 279-294, nov. 2017.

ASHIHARA, H.; ZHENG, X.Q.; KATAHIRA, R.; MORIMOTO M, OGITA. S.; SANO. H. Caffeine biosynthesis and adenine metabolism in transgenic Coffea canephora plants with reduced expression of $\mathbf{N}$-methyltransferase genes. Phytochemistry. v.67, n.9, p. 882886, mai. 2006. Disponível em: https://wwwciencedirect.ez19.periodicos.capes.gov.br/science/article/pii/S0031942206001154> Acesso em: 29 ago 2019;

AZEVEDO, J. L.; FUNGARO, M. H. P.; Vieira, C. M. L.: Transgênicos e evolução dirigida. História, Ciências, Saúde - Manguinhos, vol. VII(2), p. 451-64, jul. out. 2000. Disponível em: $\quad<$ http://www.scielo.br/scielo.php?frbrVersion=4\&script=sci_arttext\&pid=S010459702000000300014\&Ing=en\&tlng=en> Acesso em: 29 ago 2019;

BARTON C.R.; ADAMS, T.L.; ZAROWITZ, M. A. Stable transformation of foreign DNA into C. arabica plants. COLLOQUE SCIENTIFIQUE INTERNATIONAL SUR LE CAFÉ, 14. Paris. Resumos Expandidos.Paris: Association Scientifique Internacionale du Café (ASIC), 1991. p.460-464.

Disponível em: 
<http://www.scielo.br/scielo.php?script=sci_nlinks\&ref=000082\&pid=S0103-

8478201100050000300010\&lng=en> Acesso em: 29 ago 2019;

BNDES Setorial. Café: (re)conquista dos mercados. Rio de Janeiro, n. 10, p. 3-56, set. 1999; Disponível em: <https://web.bndes.gov.br/bib/jspui/bitstream/1408/1290/2/BS\%2010_final\%20A.pdf> Acesso em: 29 ago 2019;

DURÁN, C. A. A.; TSUKUI, A.; SANTOS, F. K. F; MARTINEZ, S. T.; BIZZO, H. R.; REZENDE, C. M. Café: Aspectos Gerais e seu Aproveitamento para além da Bebida. Revista Virtual de Química, ISSN 1984-6835, v. 9, N. 1, p. 107- 134, 2017.

EMBRAPA. Características das principais variedades de café cultivadas em Rondônia. Documentos 93, ISSN 0103-9865. Abril, 2004; Disponível em: <https://www.infoteca.cnptia.embrapa.br/infoteca/bitstream/doc/906832/1/Doc93cafe.pdf> Acesso em: 29 ago 2019;

FERREIRA, M.A., WALTENBERG, P. DA C.F., PINTO, E.R.DE C., DE SA, M.F.G. Use of the coffee homeobox gene cahb12 to produce transgenic plants with greater tolerance to water scarcity and salt stress. Depositante: Universidade Federal do Rio de Janeiro. BR n. 20130340113. Depósito: 08 nov. 2011. Concessão: 26 dez. 2013; Disponível em: <https://patents.google.com/patent/US20130340113A1/en> Acesso em: 29 ago 2019

INCAPER. Café conilon técnicas de produção com variedades melhoradas. 4. ed. revisada e ampliada. ISSN 1519.0528 Vitória-ES, 2012;

HATANAKA, T.; CHOI, Y. E.; KUSANO, T.; SANO, H. Transgenic plants of coffee Coffea canephora from embryogenic callus via Agrobacterium tumefaciens-mediated transformation. Plant Cell Reports, v.19, n.2, p.106-110, dez. 1999

KUMAR, V., MADHAVA NAIDU, M. \& RAVISHANKAR, G.A. Developments in coffee biotechnology - in vitro plant propagation and crop improvement. Plant Cell, Tissue and Organ Culture (PCTOC). v. 87, n.1, p.49-65, out. 2006.

LEROY, T.; HENRY, A. -M.; ROYER, M.; ALTOSAAR, I.; FRUTOS, R.; DURIS, D.; PHILIPPE, R. Genetically modified coffee plants expressing the Bacillus thuringiensis cryAc gene for resistance to leaf miner. Plant Cell Reports, v.19, p. 382-389, mar. 2000.

MISHRA, M.K., DEVI, S., MCCORMAC, A., SCOTT, N., CHEN, DF., ELLIOT,M., SLATER, A. Green fluorescent protein used as a visual selection marker for coffee transformation. Biologia. v.65, n.4, p.639-646, ago. 2010. Disponível em: <https://doiorg.ez19.periodicos.capes.gov.br/10.2478/s11756-010-0078-7> Acesso em: 29 ago 2019;

MORAIS, T. P. de; MELO, B. de. Biotecnologia aplicada ao melhoramento genético do cafeeiro. Santa Maria, v. 41, n. 5, p. 753-760, mai. 2011. Disponível em: <http://dx.doi.org/10.1590/S0103-84782011005000056> Acesso em: 29 ago 2019;

RAMAN R. The impact of Genetically Modified (GM) crops in modern agriculture: A 
review. GM Crops \& Food. v. 8, n. 4, p. 195-208, out. 2017.

REGO, B. R. \& PAULA, F. O. O mercado futuro e a comercialização de café: Influências, Riscos e Estratégias com o uso de Hedge. Revista do curso de administração/PUC Minas, ISSN 1808-6594, v.7, n.1, Art. 1, Junho de 2012;

RIBAS, A. F.; PEREIRA, L.F.P.; VIEIRA, L.G.E. Genetic transformation of coffee. Brazilian Journal of Plant Physiology. Londrina, v.18, n.1, p.83-94, Mar. 2006.

SPIRAL, J.; THIERRY, C.; PAILLARD, M.; PETIARD, V. Obtention de plantules de Coffea canephora Pierre (robusta) transformées par Agrobacterium rhizogenes. Comptes Rendus de L'Académie des Sciences, v.316, n.1, p.1-6, 1993

THOMAZINI, A.; TOMAZ, M. A.; MARTINS, L. D.; RODRIGUES, W. N. Abordagem sobre qualidade da bebida no café conilon. Enciclopédia Biosfera, Centro Científico Conhecer - Goiânia, v.7, n.12, p. 1, 2011.

SPIRAL, J.; THIERRY, C.; PAILLARD, M.; PETIARD, V. Transgenic coffee (Coffea sp.). Bajaj YPS (ed), Biotechnology in Agriculture and Forestry. Transgenic Trees, p. 55-76, Spring-Verlag, Berlim, Heidelberg, 1999. 